\title{
Anaplastic Thyroid Carcinoma with Initial Ultrasonography Features Mimicking Subacute Thyroiditis
}

\author{
Meihua Jin, Tae Yong Kim \\ Department of Internal Medicine, Asan Medical Center, University of Ulsan College of Medicine, Seoul, Korea
}

A 61-year-old man came to the Asan Medical Center for febrile sensation and neck pain. Thyroid ultrasonography (US) done at a previous hospital revealed a poorly defined and irregularly shaped hypoechogenic lesion (Fig. 1). Thyroid function testing was suggestive of subclinical hyperthyroidism and the erythrocyte sedimentation rate (ESR) level was elevated. A thyroid scan that was done at the patient's initial visit to our hospital showed severely decreased uptake without any nodules (Fig 2A). He was initially diagnosed with subacute thyroiditis (SAT) based on neck tenderness, febrile sensation, thyrotoxicosis with a decreased thyroid scan uptake rate, and a high ESR. Therefore, he was treated with prednisolone. After 7 weeks of steroid treatment, the patient gradually complained of progressive dysphagia and weight loss. We conducted thyroid US again and performed a core-needle biopsy (CNB) of the hypoechoic nodular lesion. The pathology result was necrotic tissue with a few viable atypical cells. One week later, as the dysphagia got worse, the patient was immediately admitted to the general ward. Because the neck mass was growing rapidly, he could not even swallow pills and water. We performed CNB again, and the final pathology result presented anaplastic thyroid carcinoma (ATC). Neck computed tomography showed a huge necrotic mass in both thyroid lobes compressing the airway (Fig. 2B). The patient started to take lenvatinib for palliative therapy and tracheostomy was done for airway protection. Despite the ag-

Received: 19 October 2020, Revised: 30 December 2020,

Accepted: 13 January 2021

Corresponding author: Tae Yong Kim

Division of Endocrinology and Metabolism, Department of Internal Medicine, Asan Medical Center, University of Ulsan College of Medicine, 88 Olympic-ro 43-gil, Songpa-gu, Seoul 05505, Korea

Tel: +82-2-3010-3249, Fax: +82-2-3010-6962, E-mail: tykim@amc.seoul.kr gressive treatment, the patient died of aspiration pneumonia 4 months later.

The diagnosis of SAT is based on clinical and laboratory features, and thyroid US is not mandatary for its diagnosis $[1,2]$. However, rapidly growing primary thyroid neoplasms such as ATCs, lymphomas, and other metastatic tumors can also cause neck pain by painful stretching of the gland capsule and infiltrating surrounding tissues $[3,4]$. Here we present a case of ATC with clinical symptoms, thyroid scan findings, and US features mimicking SAT. In the current case, US showed that it was a mass-forming nodular lesion distinct from SAT. Thyroid US could be considered in patients whose clinical symptoms do not improve dramatically despite treatment for SAT. US-guided biopsy may be helpful to distinguish rapidly growing masses from malignancies such as ATC.

\section{CONFLICTS OF INTEREST}

No potential conflict of interest relevant to this article was reported.

\section{ORCID}

Meihua Jin https://orcid.org/0000-0003-0196-631X

Tae Yong Kim https://orcid.org/0000-0003-4982-4441

\section{Copyright $(\underset{2021}{ } 20$ Korean Endocrine Society}

This is an Open Access article distributed under the terms of the Creative Commons Attribution Non-Commercial License (https://creativecommons.org/ licenses/by-nc/4.0/) which permits unrestricted non-commercial use, distribution, and reproduction in any medium, provided the original work is properly cited. 

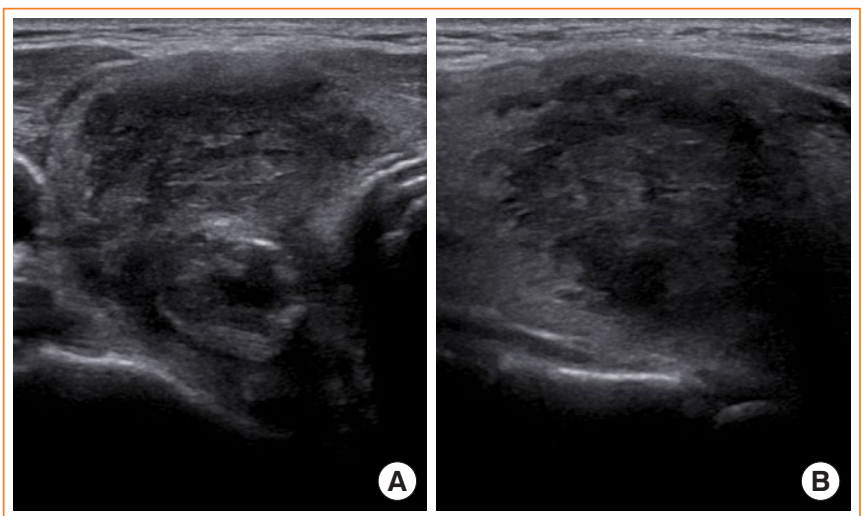

Fig. 1. Initial thyroid ultrasonography results showing a poorly defined and irregularly shaped hypoechogenic lesion. (A) Coronal view. (B) Longitudinal view.

\section{REFERENCES}

1. Bennedbaek FN, Hegedus L. The value of ultrasonography in the diagnosis and follow-up of subacute thyroiditis. Thyroid 1997;7:45-50.

2. Fatourechi V, Aniszewski JP, Fatourechi GZ, Atkinson EJ, Jacobsen SJ. Clinical features and outcome of subacute thy-

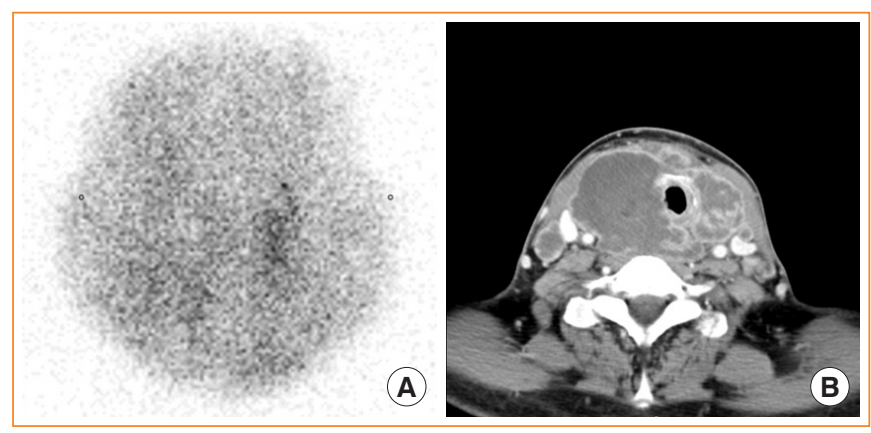

Fig. 2. Initial thyroid scan and neck computed tomography (CT) taken after the diagnosis of anaplastic thyroid carcinoma. (A) Initial thyroid scan showing severely decreased uptake. (B) Neck CT showing a huge necrotic mass in both thyroid lobes compressing the airway.

roiditis in an incidence cohort: Olmsted County, Minnesota, study. J Clin Endocrinol Metab 2003;88:2100-5.

3. Meier DA, Nagle CE. Differential diagnosis of a tender goiter. J Nucl Med 1996;37:1745-7.

4. Hamburger JI, Miller JM, Kini SR. Lymphoma of the thyroid. Ann Intern Med 1983;99:685-93. 